\title{
Method to design coordinated multiple views adapted to user's business requirements in 4D collaborative tools in AEC
}

\author{
Conrad Boton ${ }^{1,2}$, Sylvain Kubicki ${ }^{1}$, Gilles Halin ${ }^{2}$ \\ ${ }^{1}$ Henri Tudor Public Research Center, ${ }^{2}$ Research Centre in Architecture and Engineering \\ \{conrad.boton@tudor.lu, sylvain.kubicki@tudor.lu,gilles.halin@crai.archi.fr\}
}

\begin{abstract}
The issue of multiple views coordination became more and more challenging in the architecture, engineering and construction (AEC) field since the apparition and the increasing success of $4 D / n D C A D$. In order to adapt visualization to user's business requirements in $4 D$-supported collaborative tools, this paper propose a method to design coordinated multiple views based on Model-Driven Engineering (MDE).The method enables user's visualization needs description, visualization modes comparison. The aim is to choose appropriate visualization modes business needs, to associate interaction principles and coordination mechanisms in order to compose coordinated multiple views adapted to actor's business needs. The paper presents a case study based on literature review and interviews with construction sector practitioners.
\end{abstract}

Keywords--- AEC, 4D CAD, Coordinated Multiple Views, Visualization modeling, ModelDriven Engineering, CSCW, Business views.

\section{Introduction}

Coordinated multiple views (CMV) are increasingly used since their introduction and several studies have been conducted to improve their use [1-4]. But in some complex and highly collaborative fields like architecture, engineering and construction (AEC), the use of CMV deserves special attention. A major issue concerns the adaptation of views to user's business requirements in such fields. Indeed, in the construction sector, each actor usually has a specific role which follows from the partner's primary business field. It usually results in specific views used for representing building-related information [5]. Moreover, several representation modes can represent the same concepts and actors choose one or the other of these modes according to their specific needs related to the tasks they have to achieve. Then, adapting visualization to user's business needs in collaborative work supporting tools implies being able to choose the best visualization modes and to associate to them the most appropriate interaction and coordination mechanisms in order to design adapted multiple views.

Since the increasingly growing success of simulation tools based on 4D CAD (that associates a 3D view and a temporal view), the issue of multiple views composition and coordination becomes more and more important in the construction sector.

The following work relies both on Information Visualization and Human-Computer Interaction theories. It proposes a method to compose and coordinate adapted multiple views for users of 4D-based collaborative tools in construction projects.

\section{4D multiple views issue in AEC sector}

The concept "multiple views" in general describes visualizations where multiple windows are used to represent data [6]. So, "a multiple view system uses two or more distinct views to support the investigation of a single conceptual entity" [1]. Many current windowing environments treat windows as independent and isolated, and users have to manipulate individually one window at a time, even when some contents or tasks are common among the windows [7]. But we will use "coordinated multiple views" when operations on the views are coordinated [6]. In this case, the same or different portions of the data can be displayed by windows and these windows can be tightly coordinated in "a variety of ways such that interacting with one component causes meaningful effects in others" [2]. So, coordination ensures that changes in one window are propagated to all other views keeping the analyzed data consistent [8]. In designing user interfaces, multiple window coordination is more and more effective [9] and CMV strategies are gradually more used in visualization and interfaces [7].

An important capability enhanced by coordination in Information Visualization is about flexibility regarding data; selection of a type of visualization mode for a given set of data; and coordination characteristics definition [8].

The Architecture, Engineering and Construction (AEC) industry is characterized by "its loose organization of the different participants that each perform a specific role in a building project and have a 
specific view on the building project data" [5]. So, if the whole lifecycle of construction project can be covered by computer visualization usage [10], it has to support the highly collaborative aspect of the project. Indeed, in the sector, each discipline has to process a large amount of information related to the representation of a design object between disciplines. And from a stage to another, actors need to represent and share different kinds of information with various levels of abstraction [11]. Moreover, as we said, in the AEC field, several visualization modes can represent the same concept and actors choose one or the other of these modes according to their specific needs related to the task they have to perform. Indeed, cooperation assistance tools have to integrate interfaces that take into account the existence and the specificity of "business-views". "Business views" are the visualization modes that practitioners use in their daily work [12]. For example, tasks planning may be represented by a Gantt chart or by a PERT network and building elements can be depicted with a 3D model or a 2D plan. So to support the collaborative aspect of AEC projects, multiple views systems have to be adapted to users' business requirements and views have to be chosen wisely.

With the rise of 4D CAD as a reference simulation tool in the sector, the issue of coordination of multiple views becomes more important. 4D CAD consists in linking a $3 \mathrm{D}$ view of the building to a time view (works planning) to simulate the building construction over the time. Such visualizations respond to the four design rules related to diversity, complementarity, parsimony, and decomposition proposed by [1] about when to use multiple views.

The use of 4D simulation tools has a real impact in construction projects ([13]; [14]) and more recently, [15] showed that the collaborative use of $4 \mathrm{D} C A D$ is particularly useful during the pre-construction phase for comparing the constructability of working methods, for visually identifying conflicts and clashes (overlaps), and as visual tool for contractors, subcontractors and suppliers to discuss and to plan project progress. But in the framework of this collaborative use, the adaptation of 4D multi-views to users' business requirements remains a challenging issue since the classical view $(3 \mathrm{D}+\mathrm{Gantt})$ usually proposed to all practitioners in most of the current 4D tools seems not suiting the needs of every actors and situations of use.

In the next section, we propose a method aiming at designing adapted business multiple views for 4D collaborative tools in AEC sector.

\section{Method to design adapted 4D coordinated and multiple views}

\subsection{The method's steps}

We propose a multi-steps method to adapt visualization to actor's business needs in collaborative work supporting tools.

- The first step identifies the business needs of actors. This consists in formalizing the collaborative practices in order to identify the sub-practices performed by the different involved actors. Knowing these sub-practices helps to better define the business needs.

- In the framework of these collaborative practices, actors use groupware to perform their business activities. During these activities, we can identify specific usages that we have to understand and describe. The purpose of the second step is to determine the visualization needs for each actor. This step also highlights the actor's interactions and visualization tasks related to business practices. At this stage we use the taxonomy proposed by [16] to describe such visualization tasks with a single and accurate formalism (Fig. 2).

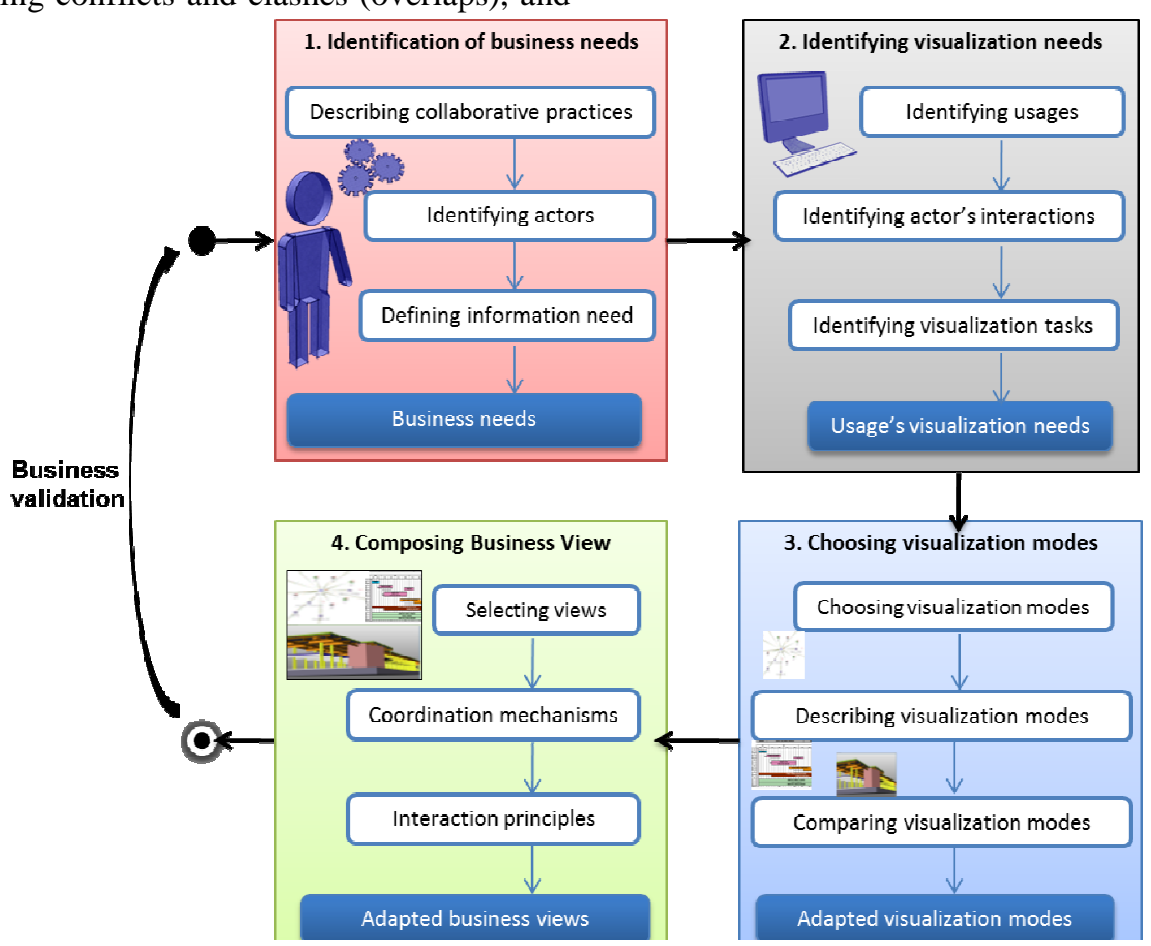

Figure 1: Method to compose business view 


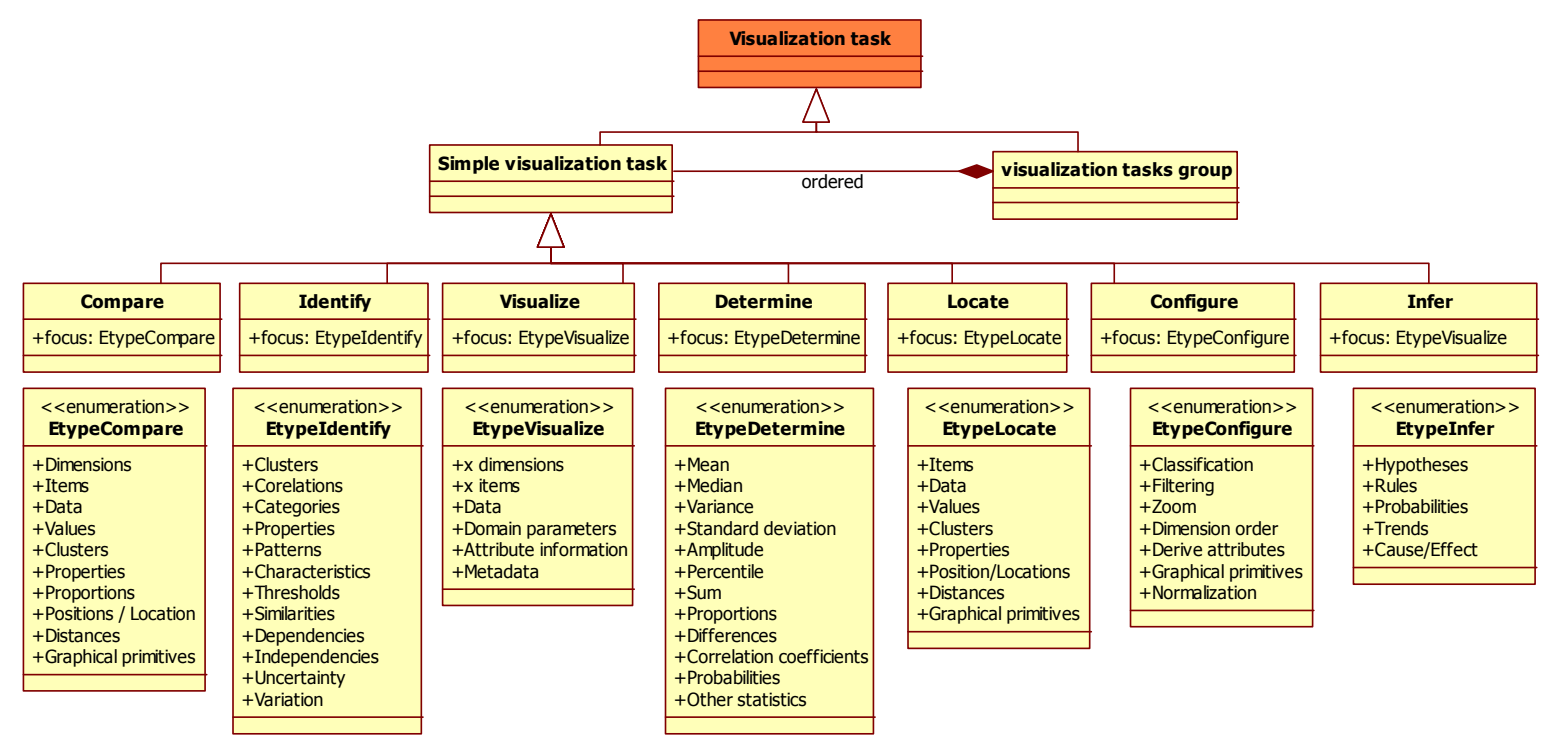

Figure 2: User's visualization tasks metamodel

- After visualization needs known, it is then possible to compare the possible visualization modes in order to choose the most appropriate in relation to the expressed needs. This is the subject of the third step in which the visualization modes are described and compared.

- When appropriate modes are selected for each actor, one can select those that may be composed together to form multiple coordinated views. To this end, it is important to study the coordination mechanisms and the interaction principles associated with the visualization modes (fourth step). At the end of this step, adapted business views are composed for each actor.

These views will then be validated to ensure that the propositions respond effectively to the expressed business needs. Fig. 1 depicts the steps of the method.

Model Driven Engineering (MDE) approach recommends the use of metamodels to define domain languages, so each model has to conform to its metamodel. In order to model visualization modes and to choose the most adapted ones, we propose to adapt and use the business view metamodel described in [17].

\subsection{Formula for visualization modes ranking}

We are working on a scoring system that would rank visualization modes according to usage needs. By assessing the criteria (technique, content, interaction principle, visualization tasks, etc.) an adaptation score (As) should be assigned to each visualization mode. This score is calculated for each actor and each sub-practice with the formula below. So, the relevance of a criterion is related to the information needs and to the visualization tasks.

$$
A s=\frac{\sum_{i=1}^{n} N c_{i}}{n}
$$

The score $\left(\mathrm{Nc}_{i}\right)$ of a criterion $i$ is then the sum of its properties relevance $\left(\mathrm{P}_{j}\right)$ scores according to a visualization requirement. The visualization requirement is both an information need and a need for visualization tasks. Nc may vary between -1 and 1 .

\subsection{Composing coordinated multiple views}

Exploration techniques and coordination control are two of the fundamental areas of coordinated and multiple views [6]. The utility of multiple coordinated views comes from users' ability to express multidimensional queries through simple forms of interaction [18]. To compose coordinated views, we use the eight guidelines proposed by [1] for the design of multiple view systems and the $2 \times 3$ taxonomy of multiple window coordination from [7]. Relied on these references and the state of the art proposed by [6], we are working to propose a metamodel of multi-views composition. This metamodel will take into account notions related to multiple views generation, exploration techniques, coordination and control, human interface and usability and perception.

\section{Case study}

We consider a case study related to site preparation collaborative context and apply our method to a specific collaborative practice: "Collaborative site scheduling". The case study is established on the basis of literature review and various interviews conducted. Indeed, we interviewed six practitioners with different roles from Luxembourg construction sector, in order to understand their common activities in the pre-construction framework and to better formalize the applied issue of this work. In this realistic case study we assume that in a given situation some actors are responsible for each of the sub-practices shown on table 1. 


\subsection{Step 1: Identifying business needs}

For the case study, we show in table 1 the result of the first step. The sub-practices which will be performed are known such as the associated responsible actors. The information needs are also identified. We see that to list building elements, the architect needs to visualize the building representation and a pre-list of building elements. The supervisor needs a work breakdown structure (WBS) and a pre-list of construction activities, to define activities and the activities planning to develop the schedule. To estimate activities duration, subcontractors will need the description on these activities while the contactor will have to visualize dates, activities durations and a building representation to create the activities sequences.

\begin{tabular}{lll}
\hline $\begin{array}{l}\text { Sub- } \\
\text { practices }\end{array}$ & $\begin{array}{l}\text { Responsible } \\
\text { actors }\end{array}$ & Information need \\
\hline $\begin{array}{l}\text { Building } \\
\text { elements } \\
\text { listing }\end{array}$ & Architect & $\begin{array}{l}\text { Pre-list of building elements, } \\
\text { building representation }\end{array}$ \\
$\begin{array}{l}\text { Activities } \\
\text { definition }\end{array}$ & Supervisor & $\begin{array}{l}\text { WBS, pre-list of construction } \\
\text { activities }\end{array}$ \\
$\begin{array}{l}\text { Activities } \\
\text { duration } \\
\text { estimation }\end{array}$ & Sub-contractors & Activities description \\
$\begin{array}{l}\text { Activities } \\
\text { sequencing }\end{array}$ & Contractor & $\begin{array}{l}\text { Dates, activities durations, } \\
\text { building representation }\end{array}$ \\
$\begin{array}{l}\text { Schedule } \\
\text { development }\end{array}$ & Supervisor & Activities planning \\
\hline
\end{tabular}

\section{Table 1: collaborative site scheduling practice}

But this is not sufficient enough to choose appropriate visualization modes. It is necessary to add the visualization tasks to be sure to take into account the actor's visualization needs.

\subsection{Step 2: Identifying visualization tasks}

After understanding the context of the $\mathrm{CP}$, the method's step 2 aims at identifying the visualization tasks the actors will have to perform. For this, subpractices are divided into elementary usages that will call for specific visualization tasks. The visualization tasks model will help us in this description as shown in table 2.

We see that to list building elements, as visualization tasks, architect will need to visualize data, locate items, and configure classifications. The activities definition will lead to visualize data, locate items, identify correlation and configure classification. To estimate activities duration, sub-contractors have to visualize data, configure filtering, determine means and infer hypotheses. For activities sequencing, contractor will visualize data, identify correlations and dependencies, infer trends, configure classifications and configure normalization. The schedule development requires visualizing data, identifying correlations, inferring trends and configuring classification.

\begin{tabular}{|c|c|c|}
\hline $\begin{array}{l}\text { Sub- } \\
\text { practices }\end{array}$ & $\begin{array}{l}\text { Elementary } \\
\text { usages }\end{array}$ & Visualization tasks \\
\hline \multirow{3}{*}{$\begin{array}{l}\text { Building } \\
\text { elements } \\
\text { listing }\end{array}$} & $\begin{array}{l}\text { Consult elements } \\
\text { pre-list }\end{array}$ & Visualize (focus: data) \\
\hline & $\begin{array}{l}\text { Find appropriate } \\
\text { elements }\end{array}$ & Locate (focus: items) \\
\hline & $\begin{array}{l}\text { Create elements } \\
\text { listing }\end{array}$ & $\begin{array}{l}\text { Configure (focus: } \\
\text { classification) }\end{array}$ \\
\hline \multirow{4}{*}{$\begin{array}{l}\text { Activities } \\
\text { definition }\end{array}$} & $\begin{array}{l}\text { Consult activities } \\
\text { pre-list }\end{array}$ & Visualize (focus: data) \\
\hline & $\begin{array}{l}\text { Consult building } \\
\text { elements }\end{array}$ & Locate (focus: items) \\
\hline & $\begin{array}{l}\text { Identify appropriate } \\
\text { activities }\end{array}$ & Identify (focus: correlations) \\
\hline & $\begin{array}{l}\text { Create activities } \\
\text { listing }\end{array}$ & $\begin{array}{l}\text { Configure (focus: } \\
\text { classification) }\end{array}$ \\
\hline \multirow{3}{*}{$\begin{array}{l}\text { Activities } \\
\text { duration } \\
\text { estimation }\end{array}$} & Consult activities & Visualize (focus: data) \\
\hline & $\begin{array}{l}\text { Understand } \\
\text { activities } \\
\text { consistency }\end{array}$ & $\begin{array}{l}\text { Configure (focus: filtering) } \\
\text { Determine (focus: means) }\end{array}$ \\
\hline & $\begin{array}{l}\text { Estimate activities } \\
\text { duration }\end{array}$ & Infer (focus: hypotheses) \\
\hline \multirow{5}{*}{$\begin{array}{l}\text { Activities } \\
\text { sequencing }\end{array}$} & $\begin{array}{l}\text { Consult activities } \\
\text { and durations }\end{array}$ & Visualize (focus: data) \\
\hline & $\begin{array}{l}\text { Study relationships } \\
\text { and dependencies } \\
\text { among activities }\end{array}$ & $\begin{array}{l}\text { Identify (focus: correlations) } \\
\text { Identify (focus: } \\
\text { dependencies) }\end{array}$ \\
\hline & Verify conflicts & Infer (focus: trends) \\
\hline & $\begin{array}{l}\text { Associate start/end } \\
\text { dates }\end{array}$ & $\begin{array}{l}\text { Configure (focus: } \\
\text { classification) }\end{array}$ \\
\hline & Define site planning & $\begin{array}{l}\text { Configure (focus: } \\
\text { normalization) }\end{array}$ \\
\hline \multirow{5}{*}{$\begin{array}{l}\text { Schedule } \\
\text { development }\end{array}$} & $\begin{array}{l}\text { Consult activities } \\
\text { listing }\end{array}$ & Visualize (focus: data) \\
\hline & $\begin{array}{l}\text { Consult actors } \\
\text { listing }\end{array}$ & Visualize (focus: data) \\
\hline & $\begin{array}{l}\text { Associate actors and } \\
\text { activities }\end{array}$ & Identify (focus: correlations) \\
\hline & Include planning & Infer (focus: trends) \\
\hline & Realize project plan & $\begin{array}{l}\text { Configure (focus: } \\
\text { classification) }\end{array}$ \\
\hline
\end{tabular}

Table 2: Actors' visualization tasks

After this step, the exact information that actors need to visualize and their visualization tasks are known. For each information need, many visualization modes may be possible. It is necessary to compare them in order to choose the best adapted ones according to actor's visualization tasks.

\subsection{Step 3: Choosing adapted visualization modes}

In this step, the business view metamodel (ref section) is used to describe the possible visualization modes for every expressed visualization need. In instance, for the sub-practice "Activities sequencing", actor need to visualize the dates, the activities durations and a building representation. The building representation could be a $2 \mathrm{D}$ plan or a $3 \mathrm{D}$ representation (Fig. 4). It is then necessary to describe these two visualization modes in order to compare them. 


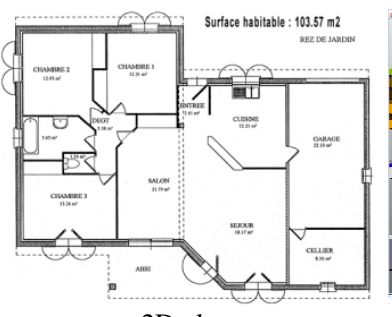

2D plan

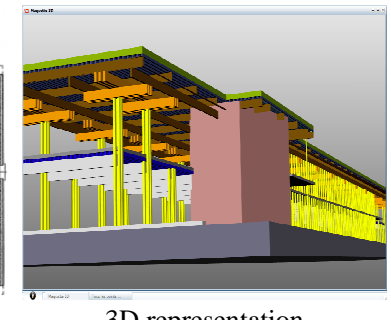

$3 \mathrm{D}$ representation
Figure 3: Some visualization modes

Table 3 shows a comparison between these two visualization modes that could be used to represent building elements. For example, 3D representation is easy to understand and more attractive than $2 \mathrm{D}$ plan. More interactions are possible with 3D representations than with $2 \mathrm{D}$ plan. At the contrary, 2D representation is widely known and used compared to 3D.

\begin{tabular}{|c|c|c|}
\hline & $\begin{array}{c}\text { 3D } \\
\text { representation }\end{array}$ & $\begin{array}{c}2 \mathrm{D} \\
\text { plan }\end{array}$ \\
\hline Technique structure & $3 \mathrm{D}$ & $2 \mathrm{D}$ \\
\hline Graphical elements & Volumes & Lines, surfaces \\
\hline Retinal attributes & $\begin{array}{c}\text { Size, Shape, Colors, } \\
\text { Form }\end{array}$ & Size, texture, Form \\
\hline Known level & Very known & Very known \\
\hline Business use level & Quite used & Very used \\
\hline Data Nature & Physical Data & Physical data \\
\hline Data spatiality & Spatial & Spatial \\
\hline Temporality & No temporal & No temporal \\
\hline Comprehensibility & Easy & Difficult \\
\hline Concrete-Abstract & Concrete & Abstract \\
\hline Attractivity & Attractive & Less attractive \\
\hline Focus & Emphasizes whole & Emphasizes parts \\
\hline Numericity & Non numeric & Non numeric \\
\hline Dynamism & Static & Static \\
\hline Possible interactions & $\begin{array}{l}\text { Interactive zoom, } \\
\text { Dynamic projection, } \\
\text { Interactive } \\
\text { deformation, } \\
\text { Link\&Brush }\end{array}$ & $\begin{array}{l}\text { Interactive zoom, } \\
\text { Interactive filtering, } \\
\text { Link\&Brush }\end{array}$ \\
\hline
\end{tabular}

Table 3: Visualization modes description

Using the adaptation score formula (table 4), we can establish that 3D representation is better suiting this subpractice. The score in Table 4 are not validated yet and future works will focus on it and, more generally, on practitioner's evaluation of business views according to our criteria and their experience. Same work for each other sub-practices will lead to know which visualization modes are appropriate. So, for each actor, all visualization modes needed to achieve his usage are known.

\begin{tabular}{|l|l|c|c|}
\hline Criteria & \multicolumn{1}{|c|}{ Proprieties } & $\begin{array}{c}\text { 3D } \\
\text { rep. }\end{array}$ & $\begin{array}{c}\text { 2D } \\
\text { plan }\end{array}$ \\
\hline \multirow{4}{*}{ Technique } & Structure & 0 & -1 \\
\cline { 2 - 4 } & Graphical elements & 1 & 0 \\
\cline { 2 - 4 } & Retinal attributes & 1 & 0 \\
\cline { 2 - 4 } & Business use & 0 & 1 \\
\cline { 2 - 4 } & $\mathbf{N c}_{\mathbf{1}}$ & $\mathbf{0 , 5}$ & $\mathbf{0}$ \\
\hline Content & Data Format & 1 & 1 \\
\cline { 2 - 4 } & Mental perception & 0 & -1 \\
\cline { 2 - 4 } & Data nature & 0 & -1 \\
\cline { 2 - 4 } & $\mathbf{N c}_{\mathbf{2}}$ & $\mathbf{0 , 3 3}$ & $\mathbf{- 0 , 3 3}$ \\
\hline \multirow{4}{*}{$\begin{array}{l}\text { Interaction } \\
\text { principles }\end{array}$} & Interaction level & 1 & -1 \\
\cline { 2 - 4 } & Interaction type & 0 & -1 \\
\cline { 2 - 4 } & $\mathbf{N c}_{\mathbf{3}}$ & $\mathbf{0 , 5}$ & $\mathbf{- 1}$ \\
\hline \multirow{4}{*}{$\begin{array}{l}\text { Visualization } \\
\text { tasks }\end{array}$} & Visualization tasks & 1 & 0 \\
\cline { 2 - 4 } & $\mathbf{N c} \mathbf{c}_{\mathbf{4}}$ & $\mathbf{1}$ & $\mathbf{0}$ \\
\hline \multirow{3}{*}{} & $\mathbf{A s}$ & $\mathbf{0 , 5 8}$ & $\mathbf{- 0 , 3 3}$ \\
\cline { 2 - 4 } & & &
\end{tabular}

Table 4: Visualization modes adaptation scores

\subsection{Step 4: Composing adapted business multi- visualization}

After selecting adapted visualization modes, a 4D tool designer would have to make sure that chosen views are compatible. This is the aim of the step 4 , and we are still working on it. We will associate appropriate exploration techniques and coordination mechanism according to the needs of each actor. That will lead to a relevant collaborative 4D tool with adapted human interfaces. For example, within the case study, the resulting multiple views could be a "3D+Gantt" visualization for the architect, a "zoomed 3D+Gantt" view with a focus on zoom for contractors and subcontractors, and a "3D + Pert" view for supervisor.

We are still working to improve this step of the method, in order to have better 4D multiple views guidelines or patterns to support it.

\section{Conclusions}

The paper presents a method to design coordinated multiple views for 4D-based collaborative tools in order to adapt visualization to user's business needs. The metamodels that support the method are also presented and a case study showed how to use these method and models.

Future works will consolidate the method and a tool will be developed to support it. Both the tool and the method will be validated through confronting it to real business situations.

\section{Acknowledgements}

This article was supported by an AFR PhD Grant funded by the National Research Fund (FNR), Luxembourg. 


\section{References}

[1] M.Q. Wang Baldonado, A. Woodruff, and A. Kuchinsky, "Guidelines for using multiple views in information visualization," AVI '00: Proceedings of the working conference on Advanced visual interfaces, New York, NY, USA: ACM, 2000, pp. 110-119.

[2] C. North, N. Conklin, K. Indukuri, and V. Saini, "Visualization schemas and a web-based architecture for custom multiple-view visualization of multipletable databases," Information Visualization, vol. 1, 2002, pp. 211-228.

[3] A. Becks and C. Seeling, "SWAPit: a multiple views paradigm for exploring associations of texts and structured data," AVI'04: Proceedings of the working conference on Advanced visual interfaces, 2004, pp. 193-196.

[4] W. Berger and H. Piringer, "Peek Brush: A HighSpeed Lightweight Ad-Hoc Selection for Multiple Coordinated Views," 2010 14th International Conference Information Visualisation, Jul. 2010, pp. 140-145.

[5] G.A. van Nederveen and F.P. Tolman, "Modelling multiple views on buildings," Automation in Construction, vol. 1, 1992, pp. 215-224.

[6] J.C. Roberts, "State of the Art: Coordinated \& Multiple Views in Exploratory Visualization," Fifth International Conference on Coordinated and Multiple Views in Exploratory Visualization (CMV 2007), Jul. 2007, pp. 61-71.

[7] C. North and B. Shneiderman, A Taxonomy of Multiple Window Coordinations, University of Maryland, College Park, Dept of Computer Science: 1997.

[8] C. North and B. Shneiderman, "Snap-Together Visualization: Can Users Construct and Operate Coordinated Visualizations?,” 2000.

[9] B. Shneiderman, Designing the user interface: strategies for effective human-computer interaction, Boston, MA, USA: Addison-Wesley Longman Publishing Co., 1997.

[10] D. Bouchlaghem, H. Shang, J. Whyte, and a Ganah, "Visualisation in architecture, engineering and construction (AEC)," Automation in Construction, vol. 14, Jun. 2005, pp. 287-295.

[11] M. Rosenman and J. Gero, "Modelling multiple views of design objects in a collaborative environment," Computer-Aided Design, vol. 28, Mar. 1996, pp. 193205.

[12] S. Kubicki, G. Halin, and A. Guerriero, "Multivisualization of the Cooperative Context in Building
Construction Activity A Model-Based Approach to design AEC-specific Visualization Interfaces,” 2007 11th International Conference Information Visualization (IV'07), Jul. 2007, pp. 590-595.

[13] S. Staub-French and A. Khanzode, "3D and 4D modeling for design and construction coordination: issues and lessons learned," ITcon, vol. vol. 12, 2007, pp. 381-407.

[14] N. Dawood and S. Sikka, "Measuring the effectiveness of 4D planning as a valuable communication tool," ITcon Vol. 13, Special Issue Virtual and Augmented Reality in Design and Construction, http://www.itcon.org/2008/39, 2008, pp. pg. 620-636.

[15] A. Mahalingam, R. Kashyap, and C. Mahajan, "An evaluation of the applicability of 4D CAD on construction projects," Automation in Construction, vol. 19, 2010, pp. 148-159.

[16] E.R.A. Valiati, M.S. Pimenta, and C.M.D.S. Freitas, "A taxonomy of tasks for guiding the evaluation of multidimensional visualizations," BELIV '06: Proceedings of the 2006 AVI workshop on BEyond time and errors, New York, NY, USA: ACM, 2006, pp. 1-6.

[17] C. Boton, S. Kubicki, and G. Halin, "Adaptation of user views to business requirements : towards adaptive views models," Proceedings of IHM 2010, the 22th International Francophone Conference on HumanComputer Interaction, Luxembourg: ACM, 2010, pp. 113-116.

[18] C. Weaver, "Look Before You Link: Eye Tracking in Multiple Coordinated View Visualization," BELIV'10: BEyond time and errors: novel evaLuation methods for Information Visualization., Atlanta, GA, USA: 2010, p. 2 p. 